\title{
O meio é a mediação: uma visão pós-fenomenológica da mediação datacrática
}

The medium is the mediation: postphenomenological views on datacratic contexts

\author{
LULI RA DFA HRERa
}

Universidade de São Paulo, Programa de Pós-Graduação em Ciências da Comunicação. São Paulo SP, Brasil

\section{RESUMO}

À medida que inovações tecnológicas transformam os processos da comunicação, a teoria das mediações de Jesus Martín-Barbero continua a ter importância nos debates epistemológicos a respeito do ambiente da comunicação em redes interativas. Mídias sociais, que, de acordo com a abordagem pós-fenomenológica, são dotadas de intencionalidade e agência moral, tornam-se as mediações preferenciais da comunicação contemporânea, transformando ambientes coletivos em datacracias, regimes em que bases de dados e algoritmos têm grande influência sobre a tomada de decisão. A teoria das mediações, ao evidenciar a importância da natureza comunicativa da cultura, mostra-se essencial na identificação da influência da comunicação na formação ideológica contemporânea.

Palavras-chave: Pós-fenomenologia, estudos tecnológicos, cultura digital, epistemologia da comunicação, datacracia

\begin{abstract}
As technological innovations transform communication processes, Jesus Martín-Barbero's theory of mediations continues to play a fundamental role in the epistemological debates about the environment of communications in interactive networks. Social media, which, according to a postphenomenological approach, have intentionality and moral agency, have become the preferential mediations of contemporary communications, turning collective environments into datacracies, regimes in which databases and algorithms have a great influence on decision making. The theory of mediations, by evidencing the importance of the communicative nature of culture, is essential to identify the influence of communication in contemporary ideological formation.
\end{abstract}

Keywords: Postphenomenology, technologic studies, digital culture, communication epistemology, datacracy 


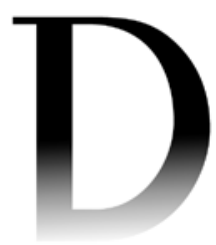

${ }^{1}$ No mundo inteiro, a audiência migra da TV para a internet, e leva com ela a verba publicitária. Relatórios como o da ZenithOptimedia detalham a migração. Disponível em: $<$ https://goo.gl/NvMDVJ>. Acesso em: 27 ago. 2017.

${ }^{2}$ Disponível em: $<$ https://goo.gl/jHB8cs $>$. Acesso em: 27 ago. 2017.

\footnotetext{
${ }^{3}$ De acordo com o ranking Alexa, que classifica os websites por número de visitantes, entre os cem endereços eletrônicos mais acessados no mundo, só a Wikipedia não é uma empresa com fins lucrativos. No Brasil, a página da Caixa Econômica Federal e a do Ministério da Fazenda acompanham a Wikipédia em português na lista dos cem websites mais populares, provavelmente por causa da consulta on-line ao Bolsa Família e da declaração do imposto de renda, respectivamente. Disponível em: <https://goo.gl/67xo2t> (ranking global) e em $<$ https://goo.gl/ET16vB> (ranking brasileiro). Acesso em: 27 ago. 2017.
}

\section{A RELEVÂNCIA CONTEMPORÂNEA DE JESÚS MARTÍN-BARBERO}

7 RINTA ANOS DEPOIS da histórica publicação de Dos meios às mediações (Martín-Barbero, 1997), a teoria de Jesús Martín-Barbero continua

extremamente relevante, mesmo levando-se em conta que as mídias de massa perderam para as mídias digitais parte significativa ${ }^{1}$ do protagonismo que tinham na época. O novo ecossistema de comunicação, apesar de inédito, não invalida a teoria. Pelo contrário, tende a reforçá-la.

$\mathrm{O}$ ambiente conectado, que surgiu como complemento do real, rapidamente tornou-se o principal componente da comunicação. Ao penetrar nas relações corporais, sociais e perceptuais com o ambiente, a tecnologia "se retirou", como define Heidegger (1977: 26), tornando-se quase transparente, deixando a configuração de objeto para tornar-se meio de experiência.

E que experiência! As mudanças ocorridas por influência da comunicação digital nas casas, empresas, escolas, ambientes de trabalho e na interação social foram tamanhas a ponto de, em menos de vinte anos, já terem acontecido transformações completas: de uma rede essencialmente técnica e acadêmica, acessada por linha telefônica, composta quase que exclusivamente por páginas de texto, a World Wide Web converte-se, inicialmente, em estrutura libertária, ainda amadora, de comunicação livre. A popularização do acesso via banda larga e, posteriormente, da conectividade via smartphones, cria uma condição de conexão permanente, o que inicialmente tenderia a reforçar os ideais de aldeia global e de democratização da mídia, uma vez que tal popularização contribuía para a diminuição de centralizadores e intermediários para a distribuição de conteúdo, ao mesmo tempo em que diminuía significativamente os custos de produção e divulgação.

As chances de negócio trazidas pela internet, no entanto, são grandes demais para serem desprezadas pelos grandes agentes econômicos, que, a partir de 2005, apressam-se a explorar as oportunidades propiciadas pelo aumento do volume de público conectado².

Pouco mais de duas décadas depois da popularização da comunicação via internet, o panorama é muito diferente daquele inspirado pelos aforismos de McLuhan. A web hoje mais se parece com um enorme conglomerado de empresas privadas, excessivamente concentradas ${ }^{3}$, cujos serviços de comunicação, profissionais e bem-acabados, são oferecidos de forma tão "gratuita" quanto o era a programação radiofônica e televisiva. Sua dinâmica, entretanto, é muito diferente da dos grandes veículos de comunicação que a precederam, resultando em mudanças consideráveis nas interações sociais, bem como nas estruturas ideológicas de persuasão.

Apesar de todas as mudanças, a formulação teórica de Martín-Barbero continua a fornecer aos pesquisadores um conjunto de conceitos para superar 
a dicotomia receptor passivo-ativo. Pois da mesma forma que os primeiros investigadores dos estudos de recepção ignoraram os aspectos socioculturais e as características do receptor, apontando os meios de comunicação como protagonistas do processo comunicacional (Canclini, 2003), muito do que é estudado no campo digital ainda traz uma visão da internet como rede livre e pública, ignorando a interferência de algoritmos de seleção e distribuição de informações no processo, ou, ainda, se preocupa demais com o tipo de equipamento utilizado ou velocidade da conexão em vez de se concentrar nas estruturas de comunicação e marketing, muitas vezes usadas como técnicas de manipulação e persuasão.

Martín-Barbero defende a abordagem da comunicação através da mediação, negando a concepção de comunicação vertical, na qual o receptor é passivamente manipulado pelo emissor:

Enquanto estratégias de interação, isto é, "modos em que se fazem reconhecíveis e organizam a competência comunicativa, os emissores e os destinatários", os gêneros não podem ser estudados sem uma redefinição da própria concepção que se teve de comunicação. Pois seu funcionamento nos coloca diante do fato de que a competência textual, narrativa, não se acha apenas presente, não é unicamente condição da emissão, mas também da recepção. (Martín-Barbero, 1997: 302)

No ambiente das mídias sociais essa visão é ainda mais importante. Organizadores da percepção, tanto no plano da existência individual como na esfera da vida coletiva, serviços de socialização como YouTube, Facebook, Twitter, Instagram e similares são muito mais persuasivos do que parecem em suas interfaces amigáveis e aplicativos multicoloridos. No contexto digital, eles são responsáveis por novas mediações culturais, deslocando boa parte das interações pessoais antes realizadas em praça pública para um ambiente incorpóreo.

O digital é o novo local em que a cultura se concretiza, ampliando as possibilidades interpretativas com as quais o receptor lida quando se apropria dos discursos da mídia. Essa influência tem componentes econômicos e políticos de grande importância. O protagonismo do comunicativo não minimiza os determinantes econômicos. Pelo contrário, evidencia-os.

Característica marcante no pensamento de Martín-Barbero, a centralidade do ser humano nos estudos da comunicação é essencial para compreender o novo ambiente social digital que, mediado por bases de dados e algoritmos dedicados de distribuição de conteúdo, se mistura ao universo da cultura e da política. Tal posição ajuda a definir o objeto da comunicação, diferenciando-o do estudo das relações e mudanças sociais - domínio das ciências sociais - ao mesmo tempo 


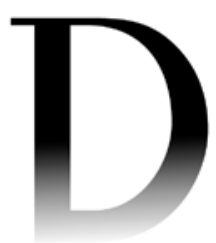

${ }^{4}$ Evgeny Morozov (2013: 6) chama de solucionismo a

"preocupação doentia de propor soluções sedutoras, monumentais e tacanhas [...] para problemas que são extremamente complexos, fluidos e contenciosos. Esses tipos de problema que, em um exame criterioso, não podem ser definidos nas formas simplificadas e abrangentes usadas pelos 'solucionadores';

o que é controverso não é a solução proposta, mas a própria definição do problema". No original: "unhealthy preoccupation with sexy, monumental, and narrow-minded solutions [...] to problems that are extremely complex, fluid, and contentious. These are the kinds of problems that, on careful examination, do not have to be defined in the singular and all-encompassing ways that 'solutionists' have defined them; what's contentious, then, is not their proposed solution but their very definition of the problem itself". Esta e demais traduções do autor.

${ }^{5}$ Pesquisa da consultoria GlobalWebIndex, empresa que compila métricas a respeito de negócios digitais, mostra que o tempo que os brasileiros passam conectados à internet via smartphones triplicou entre 2012 e 2015. Segundo o estudo, os brasileiros ficam cerca de três horas e quarenta minutos on-line pelos celulares todos os dias. Em 2012 esse número era de apenas uma hora e dezoito minutos. O Brasil ocupa a terceira colocação do ranking dos países com usuários mais tempo on-line por meio de dispositivos móveis, atrás apenas da Tailândia (quase quatro horas) e da Arábia Saudita (três horas e 48 minutos).

${ }^{6}$ Ver também: Ragon (1974: 114).

em que o diferencia do discurso positivista, solucionista ${ }^{4}$ e reducionista de grandes corporações do mercado digital, que insistem em descrever a internet como lugar utópico, alheio, não regido por regras socioeconômicas, e, portanto, imune às responsabilidades determinadas por elas.

Sob esse ponto de vista, é fundamental compreender tecnologias como instrumentos culturais, dotados de intencionalidade, responsabilidade e agência moral. Não é mais possível estar restrito ao paradigma dualista que posiciona seres humanos e artefatos tecnológicos em reinos separados, sendo estes livres e dotados de intenções, enquanto se relega aqueles à condição de meros instrumentos. A teoria das mediações possibilita investigar como a intencionalidade, a liberdade e a agência são, na realidade, resultado de sofisticadas conexões e interações entre seres humanos com e através de seus artefatos tecnológicos.

Hoje boa parte da interação social se dá pelo intermédio de tecnologias de informação e comunicação (PCs, notebooks, consoles, tablets, smartphones, etc.) e serviços digitais de relacionamento chamados de redes sociais (YouTube, Facebook, Tinder, Instagram, WhatsApp etc. $)^{5}$. Estes serviços não são simplesmente intermediários - como o telefone, o correio e o telégrafo - nem meios de comunicação e informação de massa, como o jornal, o rádio e a televisão. Por criarem ambientes de comunicação personalizada e selecionada, eles representam um papel muito mais importante e ativo do que as tecnologias que os precederam. Por esse motivo é importante refutar a ideia de que tecnologias são ferramentas neutras. É preciso buscar uma redefinição de sua agência moral e de seu papel no cotidiano.

A sociedade contemporânea deixa um sistema em que a forma seguia a função e em que os objetos podiam ser decompostos em seus componentes mecânicos para um ambiente virtualizado em que a forma não dá indicação das funções realizadas em seu interior. Não é possível, por exemplo, identificar facilmente os componentes eletrônicos de um console de videogame ou smartphone ao desmontá-los e olhar para suas peças. Hoje cada função de cada máquina conectada é a manifestação microscópica de ideias embutidas nos processos de produção e nos algoritmos residentes em seus microprocessadores que, combinados entre si e a grandes estruturas de processamento de dados on-line, geram processos complexos e de difícil acesso. Martín-Barbero já adiantava a questão: "As tecnologias não são meras ferramentas transparentes; elas não se deixam usar de qualquer modo: são em última análise a materialização da racionalidade de uma certa cultura e de um 'modelo global de organização do poder"' (Martín-Barbero, 1997: 256)

É importante ressaltar que o autor não é contrário à tecnologia, mas, segundo ele, à "logo-tecnia", que geraria "um dos mais poderosos e profundos impulsos 
para a homogeneização da vida" (Ibid.: 256). Para Martín-Barbero, a aparente simultaneidade entre a produção tecnológica e seu consumo encobre uma grande discrepância "entre objetos e práticas, entre tecnologias e usos, impedindo-nos de compreender os sentidos que sua apropriação adquire historicamente" (Ibid.: 256).

\section{NOVAS MEDIAÇÕES NO CONTEXTO DIGITAL}

Ao longo do século XX, a literatura de ficção científica atualizou a imagem do feudo medieval para um tipo de cidade modernista, isolada do ambiente externo por uma espécie de cúpula protetora ${ }^{7}$. Essa cobertura, como as muralhas e fossos medievais, teria a função de proteger seus habitantes das ameaças do mundo exterior, ao mesmo tempo em que forneceria o conforto e a infraestrutura necessária para sustentar uma comunidade.

Tais cúpulas não são mais ficção: elas já existem, invisíveis, proporcionadas pela conexão sem fio e pelos serviços de rede, onipresentes em boa parte das atividades urbanas contemporâneas. Sua estrutura, claramente paternalista, veta ou promove conteúdos de acordo com seus critérios privados ${ }^{8}$ - nem sempre claros - de publicação, pouco importando a idade ou interesse de seus usuários. Curiosamente, as mesmas redes que limitam o acesso a determinados conteúdos não demonstram pudores ao estimular o discurso de ódio ou permitir atitudes antissociais, como o preconceito, sob a desculpa pouco convincente de que "a internet é livre, não é possível administrar o conteúdo gerado pelo usuário". Ora, como é possível bloquear determinados conteúdos e não outros?

É interessante considerar que o que diferencia as concepções de proteção e encarceramento costuma ser pouco mais do que a magnitude percebida da ameaça. Em regimes totalitários, não é incomum a visão paternalista do governante a proteger seus súditos - muitas vezes à revelia deles mesmos - de agentes externos. Tal paternalismo não costuma levar em consideração que o contato com o mundo externo tem seu componente benéfico, uma vez que leva à análise crítica e à busca por melhoria, amadurecendo o usuário para o convívio social ao invés de fragilizá-lo na dependência de seu isolamento artificial que, se por acaso se romper, poderá causar problemas consideráveis.

É importante reconhecer e analisar criticamente a simbiose entre o ser humano e seus dispositivos eletrônicos antes que a influência do discurso tecnológico se torne de tal forma poderosa e abrangente a ponto de ser difícil resistir a ela, ou até mesmo identificá-la.

A influência de processos computacionais na ação humana vem crescendo progressivamente desde a popularização dos computadores pessoais. Inicialmente a máquina cumpria o papel de um assistente, com quem o tempo de trabalho ou
${ }^{7} \mathrm{O}$ clássico de Isaac Asimov

The caves of steel (1954) é referência no gênero de cidades em domos protetores, localizados em planetas próximos da Terra. Outro clássico, este contemporâneo, Neuromancer (1984) de William Gibson, responsável pela popularização de termos como hiperespaço e matrix, acontece em uma megalópole urbana nos Estados Unidos, protegida pela cúpula de um ambiente degradado. Stephen King, em seu Under the dome (2009), faz uma crítica a esse isolamento ao inverter o argumento: os habitantes de uma cidade pacata um dia se descobrem isolados do mundo por uma barreira intransponível que caiu do céu e isolou seus habitantes do resto do mundo.

${ }^{8}$ De acordo com os padrões de comunidade do Facebook, não se podem mostrar mamilos femininos, mesmo que seja em casos específicos, como amamentação. Disponível em: <https://goo.gl/zURkSi>. Não há restrições, no entanto, para o discurso de ódio de organizações terroristas como o Estado Islâmico, conforme se pode ver em várias páginas de integrantes da rede social claramente identificados. Disponível em: <https://goo.gl/GchnHW>. Acesso em: 27 ago. 2017.

${ }^{9}$ A matéria do Independent de Londres relata a controvérsia em que se viu o YouTube em março de 2017, por ter mostrado anúncios de recrutamento para o Estado Islâmico em páginas de grandes anunciantes, como McDonald's, L’Oréal, Audi, serviços governamentais e empresas de mídia, como a BBC e o jornal The Guardian. Depois de alegar que era "impossível" impedir esse tipo de anúncio, o Google voltou atrás e cortou todos os anúncios para vídeos com menos de 10 mil visualizações. Disponível em: <https://goo.gl/Vy28Bu>. Acesso em: 27 ago. 2017. 
entretenimento era compartilhado. Trabalhava-se com o computador, que era deixado no escritório ao final do expediente. O surgimento e crescente popularização dos dispositivos conectados sem fio - como notebooks, smartphones e tablets - intensificou a relação: enquanto PCs eram equipamentos compartilhados, smartphones e tablets são equipamentos pessoais, que costumam acompanhar seus usuários em seus bolsos e bolsas. Deixá-lo em casa, mesmo para uma curta jornada, costuma causar um razoável desconforto. Vive-se hoje no computador, que, como uma espécie de prótese eletrônica, raramente é abandonado.

Em um futuro próximo, a automação dos equipamentos industriais e trâmites urbanos (um processo chamado pelo mercado de cidades inteligentes), ampliará a codependência entre pessoas e máquinas. Nesse ambiente urbano conectado, cada indivíduo viverá como se estivesse dentro da máquina, uma vez que estará cercado de dispositivos de diversos tipos e tamanhos, todos a trocar informações a seu respeito. Compreender a influência de tais dispositivos no cotidiano é, portanto, essencial.

Martín-Barbero, em entrevista à Revista Pesquisa Fapesp (2009), percebe a importância da internet no que chama de "as formas mestiças da comunicação":

García Márquez, quando ganhou o Prêmio Nobel, em seu discurso começou perguntando se os povos que tinham sofrido 100 anos de solidão teriam uma segunda oportunidade sobre a terra. Eu, agora, respondo que sim. Porque aquela cultura que foi desprezada pelos intelectuais da cultura letrada, que é a cultura visual, oral, sonora e gestual, agora elas entram como cultura pela internet e se juntam no hipertexto. Como disse Manuel Castells, o computador acabou com a separação dos dois lados do cérebro: o lado da razão, da argumentação, e o lado da paixão, da imaginação, que agora estão juntos. A imaginação não é mais um poder dos poetas e dos artistas. Então, viso às novas tecnologias enquanto permitem uma apropriação que, por sua vez, permitem a hibridação, a mestiçagem das culturas cotidianas da maioria com o que era a cultura da pequena elite que tinha a escritura. (Martín-Barbero, 2009: 15)

As proposições de Martín-Barbero chamam atenção para as possibilidades criadas pela popularização dos meios de captação, produção e edição de som, imagem e texto. Se é verdade que tal popularização já seria motivo suficiente para provocar um grande crescimento no acesso às estruturas e meios de produção, o que os tornam verdadeiramente transformadores - e diferentes das mídias de massa que os precederam - é sua maleabilidade, ou a capacidade que qualquer consumidor de conteúdo comunicativo tem de armazená-los, transformá-los e compartilhá-los novamente. Como define Umberto Eco em A obra aberta (1979), o receptor se converte em sujeito da ação, ou "fruidor": 
Uma obra de arte é um objeto produzido por um autor que organiza uma seção de efeitos comunicativos de modo que cada possível fruidor possa recompreender [...] a mencionada obra, a forma originária imaginada pelo autor. Nesse sentido, o autor produz uma forma acabada em si, desejando que a forma em questão seja compreendida e fruída tal como a produziu; todavia, no ato de reação à teia dos estímulos e de compreensão de suas relações, cada fruidor traz uma situação existencial concreta, uma sensibilidade particularmente condicionada, uma determinada cultura, gostos, tendências, preconceitos pessoais, de modo que a compreensão da forma originária se verifica segundo uma determinada perspectiva individual. No fundo, a forma torna-se esteticamente válida na medida em que pode ser vista e compreendida segundo multíplices perspectivas, manifestando riqueza de aspectos e ressonâncias, sem jamais deixar de ser ela própria. (Ibid.: 53)

Em 1936, Walter Benjamin (2008: 23) escrevia seu ensaio alertando sobre o risco de a reprodução tecnológica criar uma impaciência que acabaria por destruir a "aura" da Arte e eliminar a humildade necessária para compreendê-la. Mal imaginaria ele que a deferência antes reservada às obras fosse transferida, no ambiente digital, para o equivalente de suas molduras.

Ao cultuar o poder de impacto da presença nas redes sociais - número de seguidores, quantidade de downloads, número de "curtidas" e "compartilhamentos" etc. - e dos dispositivos tecnológicos - versão, capacidade e velocidade do computador, smartphone ou tablet etc. - em vez da qualidade do conteúdo que abrigam, a condição transcendental é redirecionada para o mecanismo. O novo ritual, uma espécie de fetiche, não tem, em si, nada de arte ou de reflexão. Seu uso não encoraja o conhecimento nem estimula a descoberta. Pelo contrário, fixa pessoas a objetos e as condiciona ao modo de competição e recompensa embutido neles.

Seres humanos e artefatos tecnológicos vivem hoje de tal forma integrados que se torna cada vez mais difícil levar uma vida produtiva sem o apoio, mesmo que parcial, desses mecanismos digitais de intermediação social. Faz-se necessário, portanto, examiná-los.

\section{A NATUREZA DA MEDIAÇÃO TECNOLÓGICA}

A teoria ator-rede, de Bruno Latour (2005: 121), é indiferente quanto à natureza dos componentes de uma rede, que tanto podem ser humanos quanto não humanos, uma vez que cada componente assume sua forma em virtude das relações que estabelece. Ela defende que nada se encontra fora da rede de relações, que não há nenhuma diferença na capacidade da tecnologia, ou mesmo diferenças entre humanos, animais ou objetos em agir e desenvolver vínculos. Assim, 


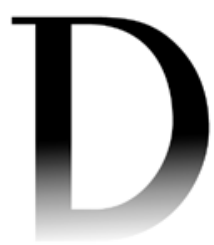

${ }^{10}$ No original: "it dissociated time from human events and helped create the belief in an independent world of mathematically measurable sequences".

${ }^{11}$ No original: "the experience of reflection induced by enlightenment is precisely the act through which the subject frees itself from a state in which it had become an object for itself".

assume que as diferenças entre cada protagonista são geradas na rede de relações, não devendo ser pressupostas. Essa análise, apesar de pertinente, é incompleta.

Lucas D. Introna (2014: 50) defende que teoria de Latour se situa no lado pragmático da estrutura pós-fenomenológica. Em seu oposto, na abordagem hermenêutica, ocorreria uma forma diferente de mediação. A ação dos objetos se daria na formatação da percepção humana, definindo a realidade para consequente interpretação, ao mesmo tempo em que se constituindo parte dela. Os atores não humanos, segundo essa perspectiva, tornam-se intérpretes da realidade, responsáveis pela relação entre os estímulos e sua percepção.

$\mathrm{O}$ uso de ferramentas tecnológicas como mediadores entre as pessoas e o ambiente que as cerca costuma provocar uma transformação significativa em seu modo de pensar. Lewis Mumford (2010: 13) descreve como o relógio mecânico, ao se popularizar no século XIV, "dissociou o tempo dos acontecimentos humanos, o que ajudou a criar a ideia de um mundo independente, baseado em sequências mensuráveis" ${ }^{10}$. Segundo ele, o quadro abstrato do Tempo dividido tornou-se ponto de referência tanto para a ação como para o pensamento.

A influência da tecnologia na sociedade é tamanha que é comum identificá-la como ameaça. De Ícaro a Fausto, do Golem a Frankenstein, o medo da tecnologia autônoma, sobre a qual há pouco ou nenhum controle, é recorrente. Ela só começa a ser vista de forma positiva, ainda que timidamente, com a ideia de desencantamento do mundo proposta por Friedrich Schiller e desenvolvida por Max Weber (1971: 270). Segundo essa linha de pensamento, à medida que os poderes da tecnologia avançam, os da natureza recuam. O misticismo tende a ser desvalorizado e a sociedade - em especial a ocidental - torna-se burocrática e secularizada. Seguindo a mesma linha de pensamento, Jürgen Habermas (1968) defende que a tecnologia é resultado do sucesso dos valores do Iluminismo, descrevendo o desencantamento do mundo como a libertação da humanidade da superstição e da ignorância, do fascínio pela natureza e seu poder arbitrário: "a experiência de reflexão induzida pelo Iluminismo é precisamente $\mathrm{o}$ ato através do qual o sujeito se livra do estado em que tinha se tornado objeto"11 (Ibid.: 247).

Resultado das transformações sociais promovidas pela Segunda Revolução Industrial, a presença ontológica da tecnologia é tema recorrente na filosofia no início do século XX. Martin Heidegger publica Sein und Zeit em 1926; John Dewey, The quest for certainty em 1929; Karl Jaspers, Die geistige Situation der Zeit em 1931; Lewis Mumford, Technics and civilization em 1934; e José Ortega y Gasset, Meditación de la técnica em 1939.

A Segunda Guerra Mundial, no entanto, trouxe de volta o medo primitivo de artefatos tecnológicos que escapassem do controle de seus 
criadores. Impressionado pelos efeitos da bomba atômica, Karl Jaspers, no ensaio The atom bomb and the future of man (1961), alerta para a capacidade tecnológica de colocar a existência humana em risco. Para superar seu demonismo seria necessário perceber a tecnologia, em última instância, como uma coleção de meios, neutros em si, utilizados para fins determinados por nós. De acordo com Jaspers, a humanidade precisaria questionar-se a respeito do que pretende fazer com a tecnologia para definir seu futuro.

A declaração de Jaspers é importante para levar em conta que a influência dos artefatos tecnológicos no comportamento humano não pode ser simplificada e resumida, pois tais artefatos não se restringem a instrumentos passivos a serem usados livremente para satisfazer propósitos moralmente bons ou perversos. Objetos tecnológicos são a materialização de intenções e, como tal, representam um papel muito ativo na definição da condição humana. Eles influenciam ativamente as ações de seus usuários, mudando a maneira como percebem o mundo e como interagem uns com os outros na construção de contextos.

A mediação tecnológica tampouco implicaria, ao contrário do que se possa imaginar, em uma limitação das liberdades humanas, nem que seja pelo simples fato da liberdade absoluta não ser possível: ações acontecem no mundo real, que constrange e limita as ações (não é possível voar, tornar-se transparente ou voltar no tempo, por exemplo). A única forma de livrar-se delas seria ignorar a realidade, o que tautologicamente impediria qualquer ação: "a ideia central da mediação moral [da tecnologia] não é a de atribuir liberdade aos artefatos, mas a de incluir seu papel mediador em nossa noção de liberdade"12 (Verbeek, 2014: 84).

Objetos não têm intenções e, nessa condição, não podem ser responsabilizados pelas ações humanas intermediadas por eles. Sua responsabilidade, quando pode ser atribuída, é de natureza causal, não moral. Como defende Verbeek, essa análise não deve ser compreendida como uma defesa do animismo, mas como "crítica ao humanismo":

Ao invés de atribuir "espírito" a objetos materiais, estudiosos que defendem a significação moral das tecnologias afastam-se de abordagens éticas que isolam e imunizam a existência humana de suas condições e contextos materiais. [...] a abordagem híbrida das relações entre homens e coisas não reduz a moralidade humana, mas a amplia, ao mostrar dimensões que normalmente permaneceriam subexpostas. Conceitualizar a significação moral dos objetos não diminui a responsabilidade humana ao culpar automóveis por acidentes, mas expande as formas que podem ser usadas para projetar, implementar e utilizar tecnologias de forma responsável ${ }^{13}$. (Ibid.: 80)
${ }^{12}$ No original: "the central idea in the approach of moral mediation is not to attribute freedom to things, but to include the mediating role of things in our notion of freedom".

${ }^{13}$ No original: Instead of claiming that material objects are "spirited", scholars who defend the idea that technologies are morally signifi cant move away from ethical approaches that isolate and immunize human existence from its material conditions and contexts. [...] hybrid approach to the relations between humans and things does not reduce human morality, but adds to it; it shows dimensions that normally remain underexposed. Conceptualizing the moral significance of things does not undermine human responsibility by blaming cars for accidents, but rather expands the ways in which we can design, implement, and use technologies in responsible ways. 
Se o efeito da ação de cada objeto depende do contexto em que é utilizado (facas podem ser utilizadas como chaves de fenda ou espátulas etc.), tecnologias precisam ser compreendidas fenomenologicamente, ou seja, com relação às diferentes formas e experiências de uso a que são sujeitas. Dessa maneira, tecnologias de informação e comunicação também podem ser interpretadas como formas tecnológicas de mediação, ao registrar e possibilitar interações entre pessoas por meio de algoritmos e bases de dados, sendo, nessa condição, muito mais complexas do que meros objetos.

Em algum ponto da segunda metade do século XX o homem começa a abrir mão de ser o senhor da máquina para viver em simbiose com sistemas eletrônicos. A eficiência produtiva dos novos mecanismos é tamanha que não causa estranheza o ato de delegar a ela todas as decisões, inclusive aquelas para as quais ela não está capacitada, como a definição de preferências e interações sociais. Processos burocráticos, padronizados em algoritmos, mudam as formas de administrar, controlar, treinar e remunerar o homem, criando, em diversas situações, o risco de desumanizarem os agentes humanos, tirando deles o que têm de mais precioso: sua capacidade de pensar e improvisar.

A sociedade contemporânea depende de sistemas computacionais para uma parcela crescente da matéria-prima usada para a vida cultural, da busca por conteúdo a formas de compartilhá-lo. Quanto mais se interage com esses sistemas, mais se prossegue em uma trajetória de codependência, criando-se uma espécie de identidade híbrida, em que o indivíduo se define através da prática digital porque os espaços virtuais se tornam mais reais em termos de experiência do que os ambientes materiais que vieram representar.

O discurso ideológico em defesa de processos sociais algorítmicos é tão comum que não é raro ouvi-lo até em analistas críticos, como Lev Manovich (2013), que defende o software como linguagem universal, "interface para nossa imaginação

${ }^{14}$ No original: "interface to our imagination and the world".

${ }^{15} \mathrm{O}$ relatório da ONU destaca a crise sanitária global, com mais de 2,5 milhões de pessoas sem saneamento básico, e busca alertar para a situação em que "mais pessoas ao redor do mundo têm telefones celulares do que sanitários". Disponível em: $<$ https://goo.gl/p5ZKY9>. Acesso em: 27 ago. 2017. e para o mundo"14. Simplificações como esta, que defende serem os algoritmos componentes primários da sociedade, podem levar a distorções significativas, como o fato de haver no mundo mais aparelhos de telefone celular do que vasos sanitários ${ }^{15}$. Ian Bogost (2015) chama a esse pensamento de "cultura algorítmica", que

está mais para uma devoção do que para um fenômeno material, uma súplica feita aos computadores. [...] tal atitude nos cega de duas formas. Primeiro, ela faz crer que qualquer transformação social promovida por computadores é algo predeterminado e inevitável, justificando a inação perante às grandes mudanças sociais promovidas por corporações gigantescas como Google ou Facebook, ao apresentar seus efeitos como algo além da nossa influência. E também por fazer-nos esquecer que determinados sistemas computacionais são abstrações, caricaturas do mundo, uma perspectiva no 
meio de muitas. O primeiro erro transforma os computadores em deuses, o segundo trata seus resultados como escrituras sagradas. [...] a cultura algorítmica [...] nada mais é do que o eufemismo para uma teocracia computacional corporativa ${ }^{16}$.

Estrategistas de líderes políticos e religiosos sempre souberam que não há ferramenta mais eficaz para a manipulação do que a ilusão de onisciência e onipotência, propriedades normalmente atribuídas a divindades externas, como deus ou a máquina - que, no momento atual, representa o papel de um deus ex machina. Livres de restrições morais e éticas, entidades externas tornam-se senhoras do destino, superiores ao formigueiro humano, ideais para controlá-lo. A liberdade é, em última instância, incompatível com a onisciência.

Mas não se pode ignorar que a própria questão da perfeição dos sistemas eletrônicos é também um mito. Até mesmo hoje, por trás de recomendações e descobertas mágicas feitas pelos aplicativos localizados em bolsas e bolsos, ainda há muito trabalho humano. Não haveria tantos engenheiros e matemáticos trabalhando nos escritórios de redes sociais como YouTube e Facebook, nem tantos funcionários carregando caixas nos armazéns em que se localizam os estoques do gigante de comércio eletrônico Amazon, nem tantos trabalhadores manuais nas fábricas que produzem os computadores e smartphones da Apple se a máquina pudesse realizar todo o trabalho sozinha.

O ideal de eficiência tecnológica, que surge como ideia que beira a excentricidade, com o tempo se mistura à sociedade que a abriga. Ela agrega os valores positivistas de eficiência aos ideais de boa vida até que estes pareçam essenciais, uma fundação quase invisível que estrutura e molda a visão de mundo, canalizando potencialidades e estabelecendo limites a seus súditos que, hipnotizados, não a questionam. Nas palavras de Martín-Barbero:

Em nome da memória eletrônica nossos povos estão sendo pressionados a renunciar a ter e desenvolver sua própria memória, já que na alternativa entre atraso e modernidade a memória cultural não conta, não é informaticamente operativa, não sendo, portanto, aproveitável. (Martín-Barbero, 1997: 254)

O código de computador permite novos processos comunicativos e, com o aumento da dimensão social da mídia em rede, propicia novas possibilidades de pensamento colaborativo. Nunca foi tão importante pensar criticamente a respeito de como o conhecimento no século XXI é codificado na mídia, em produtos e serviços de software. Mas deve-se desenvolver uma compreensão humanista da tecnologia, uma investigação a respeito do que há de humano nas relações com a máquina. Novamente Martín-Barbero traz uma reflexão precisa:
${ }^{16}$ No original: "so much as a devotional one, a supplication made to the computers [...]. This attitude blinds us in two ways. First, it allows us to chalk up any kind of computational social change as pre-determined and inevitable. It gives us an excuse not to intervene in the social shifts wrought by big corporations like Google or Facebook or their kindred, to see their outcomes as beyond our influence. Second, it makes us forget that particular computational systems are abstractions, caricatures of the world, one perspective among many. The first error turns computers into gods, the second treats their outputs as scripture. [...] algorithmic culture [...] just euphemizes a corporate, computational theocracy". 
Em vez de uma decisão política, dentre diferentes objetivos sociais possíveis, seria o caso de buscar-se uma solução tecno-científica acerca das maneiras corretas para obter-se uma finalidade pré-fixada. Para tal, seria possível prescindir do debate público; não cabe submeter à votação um fato técnico ou uma "verdade científica". O cidadão acaba sendo substituído pelo especialista. (Ibid.: 282)

Deve-se ressaltar, entretanto, que uma "solução tecno-científica" não deixa de ser uma decisão política. É política a resolução de ouvir o que a técnica tem a dizer e dar à questão, baseada em seus valores de eficiência e eficácia, peso maior do que o que seria dado a uma alternativa que considerasse o humano. Novamente mostra-se precisa a abordagem pós-fenomenológica, já que a opção pelo humano é uma decisão técnica, cuja única diferença está em valorizar mais os componentes humanos do que os financeiros ou materiais.

A reflexão dos parágrafos anteriores busca contribuir para a compreensão de parte das decisões de engenharia tecnocrática tomadas pelos governos militares que ocuparam a América Latina na segunda metade do século XX. Ela também é surpreendentemente atual quando se percebe, no discurso de candidatos a postos de comando do poder executivo ao redor do mundo, a popularidade de programas cujo ponto central é a afirmação equivocada de não serem de ordem política, o que constitui um paradoxo implícito.

${ }^{17}$ No original: “The effects of technology do not occur at the level of opinions or concepts", "alter sense ratios or patterns of perception steadily and without any resistance".

\section{REDES ANTISSOCIAIS}

Ao operar simultaneamente como espelho e janela para o mundo, estruturas computacionais de interação social moldam a forma com que seus usuários se relacionam com o mundo. Em longo prazo, elas tendem a transformar sociedades e indivíduos. "Os efeitos da tecnologia não ocorrem no nível das opiniões ou conceitos" - escreveu McLuhan - "eles alteram padrões de percepção de forma constante e sem resistência"17 (1994: 31).

Diferentemente das mídias de massa, as redes sociais eletrônicas não apenas falam para muitos como também coletam uma grande quantidade de informações a respeito de seus interlocutores, analisando detalhadamente o que os move. Cada pequena interação é registrada, classificada e analisada para gerar uma distribuição de conteúdo personalizado, capaz de atingir e mover cada usuário com grande precisão. A riqueza dessas bases de dados, aliada à sofisticação de seus algoritmos de seleção de conteúdo, hoje é usada para definir, ainda de forma paternalista, o que deve (e o que não deve) ser lido por cada um. Ao fazer que os pontos comuns sobre os quais se basearia uma discussão sensata sejam minimizados a ponto de desaparecerem, tal seleção algorítmica cria um 
natural isolamento. Ao mostrar para cada usuário apenas o que é relevante para si, essa estrutura remove do cotidiano visões alternativas que poderiam ampliar pontos de vista e promover o amadurecimento social.

Como criança mimada que vive em um ambiente controlado, ou como o súdito de um regime totalitário, o usuário de redes sociais digitais é infantilizado ao perder parte significativa de perspectiva social e ignorar a existência de fatos e opiniões contrárias às suas expectativas.

Não é por acaso que a AOL, uma das primeiras empresas a oferecer o serviço de comunidade e curadoria de conteúdo digital, apresentava seu ambiente como um walled garden para proteger seus usuários do perigoso mundo externo ${ }^{18}$. Tal terminologia paternalista se mantém até hoje. Os termos "deep web" e "darknet"19, por exemplo, usados para se referir à internet anônima - aquela que não pode ser acessada via Google -, correspondem à imagem que se faz desses ambientes, vistos como lugares perigosos e infecciosos, domínio de traficantes e criminosos, quando nada mais são do que um conjunto de redes privadas e ambientes sigilosos usados para a troca de mensagens e documentos, boa parte deles restritos a estranhos, muito parecidos com o início da internet conhecida por todos. O anonimato, é claro, facilita transações criminosas. Mas ele dificilmente é absoluto. E nada impede que operações absolutamente legais e corriqueiras sejam executadas por lá.

O isolamento do usuário de redes sociais em ambientes protegidos - problema que Eli Pariser (2011) chama de "bolha de filtro" - resulta em um conjunto de sugestões personalizadas, apresentadas com base na localização, histórico e preferências do usuário. O resultado dessa prática generalizada pode ser nocivo, principalmente se levado em conta que boa parte dos usuários desconhece sua existência e abrangência.

Com o tempo, cada indivíduo que concentre sua rede de relacionamentos e busca por informação nos pátios fechados das grandes empresas que compõem o que acredita ser a internet acaba sofrendo uma forma involuntária de alienação, promovida por bases de dados e processos algorítmicos que, em nome da relevância e da eficiência - valores positivistas - na apresentação de resultados, separam quem lê uma notícia (como ocorre na linha do tempo do Facebook e Twitter), busca uma informação (no Google ou YouTube) ou procura um livro (Amazon) ou aplicativo (Google e Apple) de resultados com os quais pode não concordar ou achar ofensivo, de forma a isolá-lo em seus próprios vieses e crenças culturais, políticas ou ideológicas. A sofisticação e a transparência do algoritmo dão a ilusão de que o indivíduo está correto em sua visão de mundo, e que seu ponto de vista é apoiado pela comunidade. Nessas condições, é natural que veja qualquer oposição como ataque bárbaro.
${ }^{18}$ De acordo com a TechTarget Network, um "walled garden" (jardim murado, em inglês) é um ambiente que controla o acesso de seus usuários ao conteúdo e serviços web. O ambiente dirige a navegação do usuário para determinadas áreas, para facilitar $\mathrm{o}$ acesso a determinados conteúdos ou restringir o acesso a outros. Disponível em: $<$ https://goo.gl/Y3F7aD $>$. Acesso em: 28 ago. 2017.

${ }^{19}$ De acordo com a Wikipédia, "Deep Web (também chamada de Deepnet, Web Invisível, Undernet, Web Obscura ou Web Oculta) se refere ao conteúdo da World Wide Web que não é indexado pelos mecanismos de busca padrão". O mesmo verbete continua dizendo que "Não deve ser confundida com a Dark Internet, que está relacionada à porção da Internet que não pode ser acessada ou que se tornou inacessível por meios convencionais. Também não se confunde com a Darknet, que não é uma simples rede de compartilhamento de arquivos, mas uma rede subjacente ou em camadas, onde existem grandes esforços no sentido de se manterem anônimos os dados de seus utilizadores". Disponível em: <https://goo.gl/TsvcWg $>$. Acesso em: 28 ago. 2017. 


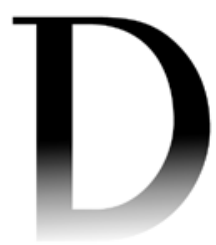

${ }^{20}$ A situação política no Brasil durante o processo de impeachment da então presidente Dilma Rousseff levou a diversas brigas em família, incensadas em parte pela mídia social. Reportagem na Folha de S.Paulo disponível em: <https://goo.gl/QNWbmy> e em $O$ Globo, disponível em: $<$ https://goo.gl/5XyaQv>. Acesso em: 28 ago. 2017.

${ }^{21}$ Da mesma forma que ocorre com outras mídias oferecidas de forma gratuita a seus receptores, nos principais serviços de mídias sociais digitais a publicidade é a principal fonte de faturamento, capaz de subsidiar o serviço e gerar grande lucratividade. $\mathrm{O}$ serviço de análise de métricas de redes sociais Hootsuite compila alguns desses dados de faturamento em <https://goo.gl/mqHWXR>. Acesso em: 28 ago. 2017.

Vive-se assim em um isolamento em grupo, em que a parábola do porco-espinho de Schopenhauer (apud Luepnitz, 2003: 117) mostra-se bastante adequada, uma vez que a necessidade de agregação social reúne os membros da rede apenas para que sejam mutuamente repelidos pelas variadas características espinhosas e desagradáveis de sua natureza. A distância moderada que os códigos de educação e boas maneiras estabeleciam em uma sociedade física desaparecem no meio digital, em que se pode abandonar conexões e buscar outras de acordo com sua conveniência ou humor ${ }^{20}$. Tudo é cada vez mais só. E espinhoso.

À medida que a conveniência dos serviços de socialização mistura-se à sua ubiquidade e intensidade de uso, a comunicação de seus usuários com o mundo externo é sacrificada. $\mathrm{O}$ acesso a múltiplos pontos de vista é restrito, e a perspectiva de opiniões e estilos de vida, limitada. Vieses e preconceitos individuais tendem a ser reforçados, relegando quem utiliza mídias sociais a uma fonte de informação pouca alternativa além da imersão em valores e conhecimentos preexistentes, reforçando uma abordagem egocêntrica da coletividade.

Nos ambientes de socialização em que o fornecimento de conteúdo está diretamente ligado às preferências do usuário, pouco há de informação ou educação, uma vez que raramente há a quebra de expectativas ou questionamento de crenças. A concretização da aldeia global a que McLuhan se referia fica mais próxima do globo a se comportar como uma aldeia do que de uma comunidade única, diversa, integrada e multicultural.

À medida que se populariza esse tipo de serviço, seus provedores transformam-se em grandes negócios, e precisam buscar usuários ao redor do planeta para divulgar mensagens publicitárias ${ }^{21}$ e sustentar planos de expansão que satisfaçam as expectativas de lucratividade de seus acionistas. Para conseguir atingir tais objetivos, o conteúdo disponível em suas redes não pode desagradar a seus usuários. Para tanto, técnicas de formatação de conteúdo de acordo com os interesses e vieses de cada usuário são reforçadas a cada nova interação com a rede, o que acaba por tornar esses ambientes mais amigáveis internamente e avessos ao estrangeiro, simultaneamente integrados e pouco diversos, características típicas de comunidades fechadas.

Ao reforçar em cada usuário a crença em suas próprias ideias, redes sociais eletrônicas diminuem a importância de qualquer comentário que se oponha a ideias preestabelecidas, buscando, muitas vezes, desqualificar seu autor. Nessa aldeia globalizada, barreiras entre casa e rua, particular e coletivo, público e privado se desfazem, dissolvendo com elas o respeito ao espaço e aos valores do próximo. 


\section{DATACRACIAS}

O cenário se complica quando se leva em conta que boa parte dos modelos sociais criados na Modernidade parece hoje demandar uma revisão. Em uma sociedade de globalização, informação, conectividade e personalização, ideias uniformizadoras a respeito de grupos de interesses, como os mercados propostos por Adam Smith ou as classes marxistas parecem generalizações grosseiras e impessoais.

Na busca por modelos de administração dos novos cenários sociais, novos projetos utilizam teorias computacionais e analisam grandes volumes de dados provenientes de comunidades digitais para tentar prever dinâmicas e tendências de interação entre grupos de pessoas ${ }^{22}$. Seu objetivo é criar modelos matemáticos para detectar anomalias nos movimentos sociais, comparar cenários e ajustar variáveis de oferta para atender a demandas tópicas.

A proposta, multidisciplinar, conecta áreas de conhecimento tão diversas quanto economia, sociologia, psicologia, comunicação, design, matemática e administração em busca de novos processos capazes de detectar, em meio ao universo de dados coletados por tantos equipamentos e serviços, padrões de comportamento mais dinâmicos do que os determinados pelos velhos coletivos de classes, profissões, bairros e partidos.

A combinação de infraestrutura social, telecomunicações, ciência política e marketing pode gerar todo tipo de efeito. A reestruturação que ela promete é muito maior do que a ocorrida na transição entre o Feudalismo e a Idade Moderna. A mudança é, de fato, tão grande que é praticamente impossível prever os efeitos e resultados das múltiplas interações e mediações que promoverá entre seus atores de diversos portes e poderes.

Porém, a compilação da informação social gerada por sensores e aplicativos onipresentes, capazes de captarem praticamente todas as formas de mediação, voluntárias ou não, com ou sem o conhecimento de seus usuários, pode resultar em uma forma de controle sem precedentes. Pela combinação entre o que é declarado - captado através das interações via equipamentos de comunicação e serviços de mídia social - e o que é feito - detectado através do uso de equipamentos, consumo de conteúdo, transações financeiras, serviços de localização e redes de contatos - será fácil saber, com elevado grau de precisão, as intenções e modos de pensar de cada indivíduo, mesmo que seja por engenharia reversa.

De posse desse conhecimento, qualquer ação de persuasão torna-se simples. Pela seleção de informação, restrição de contatos, técnicas de coerção ou uso da força, é possível mudar o comportamento de parte da população, identificar focos de oposição e eliminá-los antes que apresentem qualquer ameaça real. 


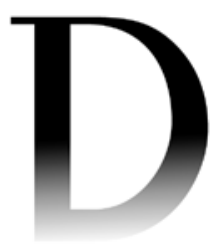

${ }^{23} \mathrm{O}$ pacote de serviços Adobe Analytics Cloud é um dos diversos serviços de análise de mercado oferecidos para empresas. Segundo seu website, a análise é capaz de promover uma "segmentação precisa em tempo real", para que "a transição dos insights para a ação seja a mais rápida possível" e "uma visão objetiva da jornada do cliente em todos os dispositivos e canais - pagos, ganhos e próprios". Disponível em: <https://goo.gl/i1RZ9v>. Acesso em: 28 ago. 2017.

${ }^{24}$ Em 2013 a SAP, gigante de software corporativo, fez uma parceria com o Fraunhofer Institute, a empresa de videogames Crytek e o clube TSG Hoffenheim, criando uma solução baseada em processamento geoespacial, sensores e visualização tridimensional para analisar os resultados de cada atleta em cada treino instantaneamente. Os uniformes portam sensores, memória para processamento local e uma pequena antena. Graças a eles, mais de 60 milhões de registros podem ser capturados, transmitidos, analisados e armazenados por jogo. História narrada pela própria SAP. Disponível em: <https://goo.gl/pJZcu3 $>$.

Acesso em: 28 ago. 2017.

${ }^{25}$ Segundo o blog da Microsoft, o metrô de Londres é automatizado por seus serviços de inteligência.

É interessante levar em conta que os dados de tráfego do maior centro comercial de um país (Reino Unido) sejam analisados por uma empresa de outro país (Estados Unidos), principalmente se considerada toda a polêmica recente com relação ao vazamento de dados dessas empresas para as agências de inteligência e espionagem norte-americanas. Disponível em: <https://goo.gl/AXzo4T $>$. Acesso em: 28 ago. 2017.

Não está claro o que pode acontecer quando tanto poder é delegado a um só operador. Como se pode ter alguma segurança da legitimidade dos objetivos de um agente com tamanha influência? Da mesma forma que os governantes dos regimes autoritários e paternalistas de obras de ficção como 1984 e Admirável mundo novo, o administrador dos processos mediados por esse tipo de algoritmo pode rapidamente tornar-se muito perigoso, paternalista, ditatorial até, de acordo com os valores embutidos ou emergentes do sistema.

Tal nível de invasão de privacidade, de fazer inveja a serviços de espionagem, não é ficção, tendência futura ou prática obscura de regimes totalitários e agências de inteligência. Ela é utilizada abertamente pela publicidade moderna ${ }^{23}$ e por grandes mercadores de informação, como redes sociais, telefônicas e instituições financeiras. A tendência analisada por Martín-Barbero ganha corpo e se mistura às próprias mediações sociais:

A partir dos anos 60, a cultura popular urbana passa a ser tomada por uma indústria cultural cujo raio de influência se torna cada vez mais abrangente, transpondo modelos em larga medida buscados no mercado transnacional. A proposta cultural se torna sedução tecnológica e incitação ao consumo, homogeneização dos estilos de vida desejáveis, banimento do nacionalismo para o "limbo anterior ao desenvolvimento tecnológico" e incorporação dos antigos conteúdos sociais, culturais e religiosos à cultura do espetáculo. Nessa tarefa, a publicidade será essencial: transforma os produtos comerciais em instituições domésticas ao mesmo tempo em que contribui para mitificar um "progresso" tecnológico que nas condições econômicas das classes populares se traduz em desvalorização cotidiana de seus saberes e suas práticas. (Martín-Barbero, 1997: 268)

Apresenta-se, então, um dilema: o uso da tecnologia melhora a qualidade dos processos sociais da atualidade, ao mesmo tempo que empobrece a relação de seus usuários com a realidade. Imerso no fluxo incessante de dados e atordoado pela intensidade e novidade das mediações, o cidadão contemporâneo está perplexo. E só. Sua comunidade foi desagregada, seu governante está preso a políticas e determinações jurídicas de outras épocas e as instituições que deveriam protegê-lo estão preocupadas demais com a sua própria sobrevivência em um ambiente excessivamente competitivo para prestarem qualquer tipo de assistência. Atordoado, ele testemunha a transformação dos tradicionais regimes cívicos em datacracias, regimes em que os processos de tomada de decisão são fortemente influenciados por bases de dados e algoritmos de busca por padrões. De treinos de futebol ${ }^{24}$ a processos administrativos ${ }^{25}$, a influência persuasiva de tais sistemas é crescente. 
É curioso notar que, em uma época de tanta transformação e revisão de modelos sociais, três ideias do século XIX ressurgem de forma digital, conectada e personalizada, apresentadas como se fossem grandes inovações, quando na verdade são propostas de redução da psique humana a um índice. São elas: darwinismo, aplicado tanto para indústrias e tecnologias quanto para a competição cruel das empresas por seus usuários no mercado global ${ }^{26}$; comunismo, com as propostas de acesso coletivo gratuito e trabalho voluntário ${ }^{27}$; e taylorismo, com a busca obsessiva por métricas absolutas de eficiência, tanto no contexto pessoal como no profissional ${ }^{28}$. A apropriação dessas ideias não passa de uma justificativa simplificada e rasteira para práticas comerciais e industriais que já deveriam, há décadas, ser extintas.

Uma abordagem pragmática, que considera o histórico e o montante de dados pessoais acumulados como mais importantes do que o depoimento do próprio indivíduo que originou tais dados tende a criar distorções de análise ${ }^{29}$, correndo o risco de remover do indivíduo o que o caracteriza como ser humano, reduzindo-o a um simples nó em uma gigantesca rede, cujo comportamento é predeterminado e inevitável. Tal redução é perigosa e alienante, uma vez que supervaloriza o algoritmo à medida que remove do cidadão o protagonismo de seu livre-arbítrio na vivência de uma democracia digital.

Conjuntos lógicos de símbolos e regras, os algoritmos deram uma grande contribuição para a ciência por serem muito mais do que um código místico ou hermético para explicar os mecanismos do universo, mas uma sintaxe lógica que fundamentou o pensamento ocidental e o que hoje se conhece por tecnologia. Mas não se pode esquecer que algoritmos também são simplificações da realidade que se propõem a medir, visto que criam abstrações para representar a complexidade do mundo em processos que capturam algumas partes de sua lógica, descartando o resto. Mesmo considerada sua complexidade, abrangência e velocidade, ainda assim não passam de conjuntos de instruções.

Em sua corrente encarnação quase mística, sistemas computacionais ganham um componente idílico - e ideológico - ao serem representados por códigos de computação perfeitos e infalíveis, capazes de analisar dados e identificar padrões de forma elegante e precisa, quase divina. $\mathrm{O}$ mesmo pode ser dito do material com que trabalha - os dados - agora rotulados como Big Data.

A mitificação dos processos sobre as idiossincrasias humanas não é nova. Em 1911, o livro Princípios da administração científica, de Frederick Taylor (2010), já continha um dos primeiros esboços explícitos e formais dos pressupostos do pensamento mundial de redução do humano a processos mecânicos. Estes incluem as crenças de que o principal, senão único objetivo do trabalho humano e do pensamento é a eficiência, e que este valor da tecnologia deveria
${ }^{26}$ A participação voluntária em testes farmacêuticos é uma prática infelizmente muito utilizada por grandes laboratórios farmacêuticos em países pobres, na busca de soluções baratas para acelerar os testes humanos, transformando populações em cobaias. Relatório do Centre for Research on Multinational Corporations (SOMO) disponível em: <https://goo.gl/g4ww13>. Acesso em: 28 ago. 2017.

${ }^{27}$ Sem o apoio do Estado ou de instituiçõoes que garantam o subsídio, essa prática não passa de uma forma camuflada de pirataria, eliminando uma importante fonte de renda para a classe artística.

${ }^{28} \mathrm{O}$ abuso nas exigências aos funcionários leva muitos trabalhadores pressionados economicamente ao desespero. Em 2010 ficou conhecida a história de dezoito tentativas de suicídio - catorze infelizmente levadas a cabo - entre trabalhadores da fábrica da Foxconn, subsidiária da Apple para a fabricação de dispositivos móveis em Shenzhen, China. A matéria do jornal inglês The Guardian explora o assunto. Disponível em: <https://goo. $\mathrm{gl} / \mathrm{PTGBzX}>$. Acesso em: 28 ago. 2017. 


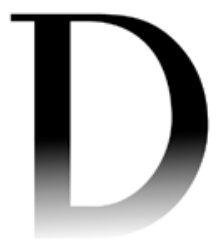

${ }^{29} \mathrm{Um}$ número crescente de pesquisas empíricas tem demonstrado que a seleção de grandes bases de dados ainda apresenta diversos defeitos e vieses de gênero, como o estudo de Zhao et al. (2017), evidenciando uma distorção sexista nos processos de aprendizagem de máquina de grandes bases de dados. Da mesma forma, o site ProPublica analisou o critério de identificação de risco de reincidência de crimes em um dos principais aplicativos de apoio ao sistema penal dos EUA, evidenciando severas distorções racistas na determinação do potencial risco social dos condenados. Essa análise está disponível em: <https://goo.gl/8ksp77>. Acesso em: 28 ago. 2017.

${ }^{30}$ No original: "two opposing world-views-the technological and the traditional-coexisted in uneasy tension. The technological was the stronger, of course, but the traditional was there-still functional, still exerting influence, still too much

alive to ignore. [...] With the rise of Technopoly, one of those thought-worlds disappears. Technopoly eliminates alternatives to itself in precisely the way Aldous Huxley outlined in Brave New World. It does not make them illegal. It does not make them immoral. It does not even make them unpopular. It makes them invisible and therefore irrelevant. And it does so by redefining what we mean by religion, by art, by family, by politics, by history, by truth, by privacy, by intelligence, so that our efinitions fit its new requirements. Technopoly, in other words, is totalitarian technocracy".

ser aplicado a todos os aspectos sociais, com valor superior ao do juízo humano. Com esses pressupostos surgem algumas propostas tristemente conhecidas: "o julgamento humano, por ser ambíguo e complexo, não é confiável”; "a subjetividade é um obstáculo"; "o que não pode ser medido não existe ou não tem valor"; e "os assuntos sociais serão mais bem tratados se forem administrados por especialistas". A especialização e mecanização do trabalho substituem a artesania e eliminam a humanidade. Neil Postman chama esse processo de ditadura do tecnopólio:

duas visões opostas de mundo - a tecnológica e a tradicional - coexistiam em tensão desconfortável. A tecnológica era mais forte, é claro, mas a tradicional ainda se mantinha - ainda funcional, ainda a exercer influência, ainda muito viva para ser ignorada. [...]

Com a ascensão do tecnopólio, uma dessas visões de mundo desaparece. O tecnopólio elimina as alternativas a ele da forma que Aldous Huxley descreve em Admirável mundo novo. Ele não as torna ilegais. Ele não as torna imorais. Ele nem as torna impopulares. Ele as torna invisíveis, e, portanto, irrelevantes. E o faz ao redefinir o que consideramos religião, arte, família, política, história, verdade, privacidade e inteligência, de forma que nossas definições se adaptem a suas novas demandas. Tecnopólio, em outras palavras, é a tecnocracia totalitária ${ }^{30}$. (Postman, 1993: 31)

Segundo Postman, a informação, principal produto de um tecnopólio, é deificada, tornando-se tanto o meio quanto a finalidade da vida humana. Tecnologias de informação e comunicação são desenvolvidas para resolver um problema que não existia ou não era crucial: sua escassez. Novas formas de misticismo são desenvolvidas para dar à informação vida própria (Technium ${ }^{31}$ ) ou transformá-la em arrebatamento (Singularidade ${ }^{32}$ ). Ela não parece resolver, no entanto, os problemas do mundo. Guerras, subnutrição e desigualdade não são resolvidas com acréscimo de informação, que pode até ter o efeito contrário, estimulando conflitos entre populações miseráveis pela conquista de minérios raros para fabricar os novos telefones ${ }^{33}$, ou submetendo trabalhadores a condições subumanas no trabalho de manufatura e reciclagem de materiais ${ }^{34}$.

Insensível a essa inflação de dados e obesidade de informaçãa $0^{35}$, a cultura contemporânea insiste que ainda não há o suficiente, e busca por mais, cada vez mais ${ }^{36}$. Postman (1993: 113) defende que, com o "tecnopólio", o progresso humano é substituído pelo tecnológico. O objetivo maior não é mais reduzir o sofrimento, mas atender às exigências da máquina compiladora e organizadora da informação. Perde-se a confiança no julgamento humano e em sua interpretação de subjetividades. Desvaloriza-se a capacidade única de ver situações por 
todas as suas dimensões emocionais, morais ou psicológicas. Tudo é substituído pela fé na técnica.

Nesse tipo de sociedade, quem controla os dados passa a ter o verdadeiro poder. Da mesma forma que os catequizadores europeus faziam em solo indígena, os conquistadores dos grandes impérios digitais fascinam os nativos com suas interfaces. Como se fazia no Circo Máximo, a comunidade é distraída com a humilhação do próximo e jogos fúteis, enquanto informações pessoais são coletadas e comercializadas inescrupulosamente. O circo é tão eficiente que dispensa a distribuição de pão.

\section{A ABORDAGEM PÓS-FENOMENOLÓGICA}

A neutralidade da tecnologia é um equívoco. Engano similar é sua divinização, como se todas as técnicas fossem diferentes manifestações de uma só entidade, que teria a mesma grandeza que a natureza ou a humanidade. A tecnologia é, no máximo, um indicativo de categoria de artefato, tão diverso, genérico, interdependente e multidisciplinar quanto a arte. Ambígua e contraditória em sua essência, ela é tão imprevisível quanto qualquer outro desenvolvimento cultural humano. A ideia de aparelhos tomando decisões por pessoas é, em sua essência, incompatível com a liberdade humana. E tem fortes contornos totalitários.

A visão pós-fenomenológica (Verbeek, 2014: 80) defende que, quando uma tecnologia é usada, ela não só interfere nas ações humanas, como também formata experiências e comportamentos. Por sua complexidade e influência, as tecnologias demandam, como sugere Philip Brey (2014), uma ética estrutural, similar e complementar àquela que se dedica aos agentes humanos. Tal divisão da ética trataria de aspectos morais de estruturas e redes, de seu impacto nos seres humanos e na relação entre agentes humanos e não humanos. Segundo Brey (2014: 135):

A proposta da ética estrutural é estudar os arranjos sociais e materiais, bem como os componentes desses arranjos, artefatos e agentes humanos. [...] No processo, ela também busca identificar, avaliar e propor papéis dos elementos individuais desses arranjos. Diferentemente da ética individual, a ética estrutural examina as grandes estruturas e redes com o objetivo de engajá-las na engenharia social e tecnológica ${ }^{37}$.

Brey defende que os fatores morais podem ser voltados a resultados ou comportamentos, e que os que buscam o primeiro tipo têm forte influência - positiva ou negativa - nos efeitos sociais e posteriores avaliações morais causadas por eles. Fatores morais voltados a resultados costumam estar em equipamentos industriais ou comerciais que buscam aumentar a eficiência, mas que podem, no processo,
${ }^{31}$ Kevin Kelly, ex-editor da revista de cultura tecnológica Wired e analista de tecnologias, cunhou o termo para se referir a "um sistema emergente, também chamado de "Tecnologia" com ' $\mathrm{T}$ ' maiúsculo', que tem seus próprios objetivos e demandas, como qualquer sistema grande e complexo, de fato, como a própria vida”. Disponível em: <https://goo.gl/hWv4MG>. Acesso em: 28 ago. 2017.

${ }^{32}$ Ray Kurtzweil, inventor e cientista da computação, propõe a singularidade tecnológica, uma hipótese de que a evolução da inteligência artificial chegaria a um ponto em que ela ultrapassaria a inteligência combinada de todos os seres humanos no planeta, resultando em um superorganismo com poderes divinos. Disponível em: <https://goo.gl/FXzXPn>. Acesso em: 28 ago. 2017.

${ }^{33}$ Uma reportagem da revista The Atlantic alerta para uma possível causa de guerra no Congo: a extração de minerais para a produção de smartphones. Disponível em: <https://goo.gl/smpMW7>. Acesso em: 28 ago. 2017.

${ }^{34}$ A National Geographic relata o perigoso processo de reciclagem de navios em Bangladesh. Disponível em: <https://goo.gl/72R4r7>. Acesso em: 28 ago. 2017.

${ }^{35}$ Clay Johnson propõe uma "dieta de informação", ao constatar que o consumo excessivo de informação - que ele compara com o consumo excessivo de alimentos - leva a confusão e atordoamento. O problema, no entanto, não está na vítima, mas no provedor de informação. Bibliotecas e bancas de jornal nunca provocaram esse tipo de confusão. Disponível em: $<$ https://goo.gl/tr59sS $>$. Acesso em: 28 ago. 2017. 


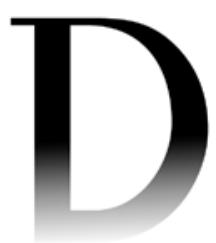

${ }^{36}$ Diversos analistas técnicos preveem que em 2017 serão gerados e armazenados mais dados do que em toda a história. Disponível em: $<$ https://goo.gl/auUv2P>. Acesso em: 28 ago. 2017.

${ }^{37}$ No original: "Structural ethics studies social and material arrangements as well as components of such arrangements, such as artifacts and human agents. [...] In doing so, it also aims to identify, evaluate and prescribe roles of individual elements in these arrangements. Unlike individual ethics, structural ethics hence looks at larger structures and networks with the aim of engaging in social and technological engineering".

${ }^{38} \mathrm{O}$ sistema operacional Android tem cerca de 12 milhões de linhas de programação. Disponível em: <https://goo.gl/4cxVE5>. Acesso em: 27 ago. 2017.

causar em seus usuários lesões de esforço repetitivo. Já os fatores morais voltados a comportamentos têm impacto mais sutil. Eles podem diminuir o foco, aumentar a insegurança ou impor ideais de eficiência nas relações humanas.

A identificação dos fatores morais proposta por Brey é oportuna em um ambiente em que máquinas deixam de ser ferramentas para se tornarem intermediários sociais. Em um futuro próximo, cidades e governos estarão automatizados a ponto de ser impossível realizar qualquer função burocrática sem sua intervenção. Antes que este momento chegue é importante questionar qual é o objetivo moral da tecnologia. O que ela considera sucesso? Qual é o peso de suas variáveis? Que importância é dada ao componente humano? Seus processos são abertos, transparentes e editáveis? Como eles são comunicados? De que forma suas intermediações interferem nas decisões humanas? Em outras palavras, o que ela toma por princípios éticos? Não são poucas as perguntas, e as respostas até agora não são claras. É essencial, no entanto, formulá-las, porque estamos, como o personagem de Ionesco, cercados de rinocerontes tecnológicos a ocupar brutalmente o espaço cotidiano, contaminando-o com visões pragmáticas de eficiência, nas quais pouco sobra de humano além do erro.

O contexto social é progressivamente composto e amplificado por objetos ditos inteligentes, dependentes de decisões de elevado grau de sofisticação, realizadas por algoritmos compostos de coleções de módulos integrados a outros módulos, chegando a níveis de complexidade impensados e ininteligíveis para o ser humano. O sistema operacional de um smartphone, por exemplo, tem mais de dez milhões de linhas de programação ${ }^{38}$. Resultado do trabalho de equipes volumosas, parte dele é baseado em sistemas de código aberto, que por sua vez são desenvolvidos por milhares de profissionais, muitas vezes anônimos, espalhados pelo mundo.

Vendem-se abstrações como computação em nuvem, inteligência artificial e resultados em tempo real como se fossem produtos sintéticos, de geração espontânea, racionais e sábios. São entregues, no entanto, as idiossincrasias de uma obra coletiva de cérebros, mãos e corpos humanos, com dúvidas e imperfeições, vieses e valores, preconceitos e vícios, caoticamente aglutinados, conectados e magnificados por sistemas incapazes de compreendê-los.

Presos a uma associação por conveniência, homem e máquina vivem uma relação tumultuosa. Quando a máquina finalmente abandona seu estágio bruto e dá sinais de interpretação dos sinais humanos, ela se torna tão complexa que não há uma só pessoa que a compreenda por inteiro. Combinados, homem e máquina criam híbridos complexos, esfinges de lógica difusa e comportamento errático - que, de forma opaca, funcionam. 
De acordo com a abordagem pós-fenomenológica, os artefatos técnicos misturam-se aos agentes humanos no convívio social e, na qualidade de agentes, tornam-se suscetíveis à avaliação moral: como acontece com seres humanos, artefatos técnicos e suas ações podem ser qualificados como moralmente bons ou ruins. Nesta visão, a imagem de objetos como instrumentos passivos, moralmente neutros, é substituída por outra na qual sua agência moral é presente. Como pessoas, objetos podem ser classificados como bons ou maus, e esta avaliação apresenta pouca relação com sua qualidade técnica. Pode ser quase impossível achar um bom revólver sob essa ótica, mas um mau travesseiro pode proporcionar excelentes noites de sono e, ao mesmo tempo, causar um eventual sufocamento.

$\mathrm{Na}$ realidade mediada pelas tecnologias digitais, sociais e interativas, produtos, serviços, relações e bens se desmaterializam, são traduzidos em informação e se tornam quantificáveis. Ações contextuais ajustam ambientes e mediações de acordo com o uso, humor, preferências, hábitos e recomendações sociais de seus usuários. A experiência, cada vez mais integrada, torna a internet (e as forças comerciais, de persuasão, influência e dominação que circulam por ela) quase invisível.

Unificado ao fluxo de dados que o cerca, o indivíduo contemporâneo vê a tecnologia digital transformar-se em sua mediação preferencial e, nesse processo, mudar de natureza. A máquina e os serviços propiciados por ela transformam-se em ponto de referência, únicos símbolos compartilhados em sociedades compostas por estrangeiros, em que as relações comunitárias do passado se dissolvem.

A interação com a máquina hoje, apesar de significativamente melhor do que há algumas décadas, ainda é primitiva. Ainda é possível identificar os momentos em que essa interação ocorre e tentar, mesmo que de forma ingênua, prescindir de sua presença, desligando o celular, por exemplo. Logo esta comunicação se tornará pervasiva, envolvendo o contexto social com intensidade e frequência nunca vistas.

Interagindo com atores cuja origem e intenção nem o ser humano mais qualificado será capaz de desmascarar, todos estarão dependentes de uma nova epistemologia das mediações com a máquina. Derivada de correntes como a pós-fenomenologia, ela tenderá a se expandir para além dos meios, questionando a verdadeira natureza mediática.

Neste contexto, cada meio passa a ser constituído e transformado pelos conteúdos e mediações que recebe, traduz, recicla, assimila e compartilha de outros meios. Não será mais possível questionar a natureza da mediação sem inquirir a respeito da natureza do meio que a abriga. Em última instância, meio e mediação tenderão a ser igualmente fluidos, indefiníveis e 
indissociáveis. Ao chegar a este ponto, o meio será a mediação. Como disse Martín-Barbero (2009: 163), e

se, em lugar de pensar a comunicação como dominação, pensássemos a dominação como processo de comunicação? Porque Gramsci me ensinou que a dominação é de dois tipos. Primeiro, há a repressão bruta [...] essa dominação é como a relação entre a bota do militar e a barata, entre uma e outra não pode haver uma relação senão de esmagamento, e a barata tem que correr. Mas Gramsci nos ensinou também a noção de dominação como hegemonia, e a hegemonia é feita de cumplicidade, de sedução, de fascinação. E há que se pensar sobre "o que, nos dominados, trabalha a favor do dominador". M

\section{REFERÊNCIAS}

ASIMOV, I. The caves of steel. New York: Doubleday, 1954.

BENJAMIN, Walter. The work of art in the age of its technological reproducibility and other writings on media. London: Harvard University Press, 2008.

BOGOST, I. The cathedral of computation. The Atlantic, Washington, D.C., 15 jan. 2015. Disponível em: <https://goo.gl/q1snJz>. Acesso em: 27 ago. 2017.

BREY, P. From moral agents to moral factors: the structural ethics approach. In: KROES, P.; VERBEEK, P. (Eds.). The moral status of technical artefacts. Dordrecht: Springer, 2014. p. 125-142.

CANCLINI, N. G. Culturas híbridas. 4. ed. São Paulo: Edusp, 2003.

ECO, U. Obra aberta: forma e indeterminação nas poéticas contemporâneas. São Paulo: Perspectiva, 1979.

GIBSON, W. Neuromancer. New York: Ace Books, 1984.

HABERMAS, J. Knowledge and human interests. Boston: Beacon Press, 1968.

HEIDEGGER, M. The question concerning technology \& other essays. New York: Garland, 1977.

INTRONA, L. D. Towards a post-human intra-actional account of sociomaterial agency (and morality). In: JOHNSON, C. The information diet. San Francisco: O'Reilly Media, 2015. p. 31-53.

JASPERS, K. The atom bomb and the future of man. Chicago: University of Chicago Press, 1961.

KELLY, K. What technology wants. New York: Penguin Group, 2010.

KING, S. Under the dome. New York: Scribner, 2009.

KROES, P.; VERBEEK, P. (eds.). The moral status of technical artefacts. Dordrecht: Springer, 2014. 
LATOUR, B. Reassembling the social: an introduction to actor-network theory. New York: Oxford Press University, 2005.

LUEPNITZ, D. Schopenhauer's porcupines: intimacy and its dilemmas: five stories of psychotherapy. New York: Basic Books, 2003.

MANOVICH, L. The algorithms of our lives. The Chronicle of Higher Education, Washington, D.C., 16 dez. 2013. Disponível em: <https://goo.gl/oAvjTK>. Acesso em: 27 ago. 2017.

MARTÍN-BARBERO, J. Dos meios às mediações: comunicação, cultura e hegemonia. Rio de Janeiro: Editora da UFRJ, 1997.

As formas mestiças da mídia: entrevista concedida a Mariluce Moura. Revista Pesquisa Fapesp, São Paulo, n. 163, p. 10-15, set. 2009.

MCLUHAN, M. Understanding media: the extensions of man. London: MIT Press, 1994.

MOROZOV, E. To save everything, click here. New York: PublicAffairs, 2013.

MUMFORD, L. Technics and civilization. Chicago: University of Chicago Press, 2010.

PARISER, E. The filter bubble: what the Internet is hiding from you. New York: Penguin Press, 2011.

POSTMAN, N. Technopoly: the surrender of culture to technology. New York: Vintage Books, 1993.

RAGON, M. Histoire de la littérature proletarienne en France. Paris: Albin Michel, 1974.

TAYLOR, F. Princípios de administração científica. 8. ed. São Paulo: Atlas, 2010. VERBEEK, P. Some misunderstandings about the moral significance of technology. In KROES, P., VERBEEK, P. (Eds). The moral status of technical artefacts. Dordrecht: Springer, 2014. p. 75-88.

WEBER, M. The sociology of religion. Boston: Beacon Press, 1971.

ZHAO, J. et al. Men also like shopping: reducing gender bias amplification using corpus-level constraints. In: CONFERENCE ON EMPIRICAL METHODS IN NATURAL LANGUAGE PROCESSING, 2017, Copenhagen. Proceedings... 2017. Disponível em: <https://goo.gl/K3abry>. Acesso em: 28 ago. 2017.

Artigo recebido em 29 de agosto de 2017 e aprovado em 10 de novembro de 2017. 